\title{
IMPLEMENTASI KOMBINASI ALGORITME SELF-ORGANIZING MAP DAN FUZZY C-MEANS UNTUK PENGELOMPOKAN PERFORMA BELAJAR SISWA PADA MEDIA PEMBELAJARAN DIGITAL
}

\author{
Nabila Divanadia Luckyana*1, Ahmad Afif Supianto², Tibyani $^{3}$ \\ ${ }^{1,2,3}$ Teknik Informatika, Fakultas Ilmu Komputer, Universitas Brawijaya \\ Email: 1divadivanadia@student.ub.ac.id, 2afif.supianto@ub.ac.id, ${ }^{3}$ tibyani@ub.ac.id \\ *Penulis Korespondensi
}

(Naskah masuk: 24 November 2020, diterima untuk diterbitkan: 09 Juni 2021)

\begin{abstract}
Abstrak
Media pembelajaran digital mampu menyimpan data dalam bentuk log data yang dapat digunakan untuk melihat perbedaan performa siswa yang tentu saja berbeda-beda antara satu siswa dengan siswa yang lainnya. Perbedaan performa siswa tersebut menyebabkan dibutuhkannya sebuah tahapan yang berfungsi untuk mempermudah proses evaluasi dengan cara menempatkan siswa kedalam kelompok yang sesuai agar dapat membantu tenaga pengajar dalam menangani serta memberikan umpan balik yang tepat pada siswanya. Penelitian ini bertujuan memanfaatkan $\log$ data dari sebuah media pembelajaran digital dengan menggunakan kombinasi dari algoritme Self-Organizing Map dan Fuzzy C-Means untuk mengelompokan siswa berdasarkan aktivitas mereka selama belajar dengan media tersebut. Data akan melalui sebuah proses reduksi dimensi dengan menggunakan algoritme SOM, lalu dikelompokkan dengan menggunakan algoritme FCM. Selanjutnya, data dievaluasi dengan menggunakan nilai silhouette coefficient dan dibandingkan dengan algoritme SOM clustering konvensional. Berdasarkan hasil implementasi yang telah dilakukan menggunakan 12 data assignment pada media pembelajaran Monsakun, dihasilkan parameter-parameter optimal seperti ukuran map atau jumlah output neuron sejumlah $25 \times 25$ dengan nilai learning rate yang berbeda-beda disetiap assignment. Selain itu, diperoleh pula 2 kelompok siswa pada setiap assignment berdasarkan nilai silhouette coefficient tertinggi yang mencapai lebih dari 0.8 di beberapa assignment. Melalui serangkaian pengujian yang telah dilakukan, penerapan kombinasi algoritme SOM dan FCM secara signifikan menghasilkan cluster yang lebih baik dibandingkan dengan algoritme SOM clustering konvensional.
\end{abstract}

Kata kunci: clustering, performa belajar siswa, media pembelajaran, Self-Organizing Map, Fuzzy C-Means, SOM-FCM.

\section{IMPLEMENTATION OF SELF-ORGANIZING MAP AND FUZZY C-MEANS ALGORITHM COMBINATION FOR STUDENT' PERFORMANCE CLUSTERING IN DIGITAL LEARNING MEDIA}

\begin{abstract}
Digital learning media is able to store data in the form of log data that can be used to see differences in student performance. The difference in student performance causes the need for a stage that functions to simplify the evaluation process by placing students into appropriate groups in order to assist the teaching staff in handling and providing appropriate feedback to students. This study aims to utilize log data from a digital learning media using a combination of the Self-Organizing Map algorithm and Fuzzy C-Means to classify students based on their activities while learning with these media. The data will go through a dimensional reduction process using the SOM algorithm, then grouped using the FCM algorithm. Furthermore, the data were evaluated using the silhouette coefficient value and compared with the conventional SOM clustering algorithm. Based on the results of the implementation that has been carried out using 12 data assignments on the Monsakun learning media, optimal parameters such as map size or the number of neuron outputs are 25x25 with different learning rate values in each assignment. In addition, 2 groups of students were obtained for each assignment based on the highest silhouette coefficient score which reached more than 0.8 in several assignments. Through a series of tests that have been carried out, the implementation of a combination of the SOM and FCM algorithms has significantly better clusters than the conventional SOM clustering algorithm.
\end{abstract}

Keywords: clustering, student learning performance, learning media, Self-Organizing Map, Fuzzy C-Means, SOM-FCM. 


\section{PENDAHULUAN}

Media pembelajaran dalam sebuah arti luas merupakan suatu media yang dapat digunakan untuk menunjang proses belajar. Menurut Sadiman (2008) media pembelajaran merupakan perpaduan dari alat dan bahan yang dapat menyalurkan pesan yang bertujuan untuk meraih minat dari penerima pesan tersebut. Media pembelajaran juga membuat proses belajar memiliki metode yang lebih bervariasi dan dapat membantu meningkatkan motivasi untuk belajar. Dalam sebuah proses pembelajaran, seringkali siswa dituntut untuk aktif dan mandiri, namun kemampuan setiap siswa yang berbeda membuat tenaga pengajar harus mampu mengawasi dan mengetahui sejauh mana perkembangan siswanya agar tidak ada siswa yang tertinggal. Pada era modern saat ini marak dikembangkan media pembelajaran digital sebagai alat bantu dalam menunjang proses pembelajaran (Muhasim, 2017). Tenaga pengajar dapat mengawasi dan mengetahui perkembangan siswa melalui rekaman aktivitas siswa saat menggunakan media pembelajaran digital (Supratman \& Purwaningtias, 2018).

Sebuah media pembelajaran digital berbasis aritmatika bernama Monsakun mampu merekam kegiatan pengguna yang terjadi didalamnya dan menghasilkan log data (Supianto, dkk., 2016). Log data tersebut dapat diolah untuk berbagai kepentingan, seperti mengevaluasi proses belajar dari pengguna media pembelajaran itu sendiri. Evaluasi terhadap tingkah laku siswa saat menggunakan suatu media pembelajaran digital dapat membantu tenaga pengajar mengukur performa siswa dalam belajar. Melalui data tersebut, nantinya peranan dari media pembelajaran pun dapat terlihat. Pengolahan data terkait permasalahan tersebut dapat dilakukan dengan melakukan pengelompokan.

Sebelumnya, sebuah penelitian telah melakukan pengolahan pada log data yang dihasilkan oleh Monsakun untuk mengidentifikasi performa belajar siswa. Dalam penelitian ini, analisis dilakukan secara manual dengan mengambil kesimpulan melalui visualisasi dan persepsi peneliti. Siswa dikelompokkan menjadi empat kelompok berdasarkan pola siswa dalam menyelesaikan permasalahan dalam Monsakun. Hasil pengelompokan dapat mengatakan bahwa siswa disetiap kelompok membutuhkan perlakuan yang berbeda-beda. (Supianto, dkk., 2019). Penelitian ini membuktikan bahwa pengelompokan penting dilakukan untuk mendapatkan umpan balik yang tepat sebagai dasar melakukan evaluasi dalam sebuah proses pembelajaran.

Di sisi lain, sebuah penelitian dengan adaptasi lebih lanjut dari pengelompokan performa belajar siswa juga telah dilakukan. Pengelompokan dilakukan secara otomatis dengan menggunakan salah satu teknik yang ada dalam data mining, yakni algoritme Self Organizing-Map (SOM) (Alias, dkk.,
2017). Pada penelitian tersebut, SOM berhasil digunakan untuk mengelompokkan log data siswa berdasarkan interaksi dan aktivitas siswa tersebut ketika menggunakan E-Learning pada mata pelajaran Algoritme dan Struktur Data. Atribut yang dimiliki oleh log data dipilih menggunakan Principal Component Analysis (PCA) terlebih dahulu sebelum kemudian diproses dengan SOM. Kemudian melalui proses tersebut, dihasilkan Low Browsing cluster dan High Browsing cluster. Adapun pengujian yang dilakukan dalam penelitian ini dengan menggunakan Silhouette index, Dunn index, dan Davies-Bouldin index dan membandingkannya dengan $K$-Means dan Partitioning Around Medoids dan memunculkan SOM sebagai algoritme pemenang.

Walaupun SOM merupakan algoritme yang cukup baik untuk melakukan proses clustering sekaligus memvisualisasikan hasilnya, SOM seringkali menimbulkan ambiguitas mengenai batasan-batasan dari cluster yang dihasilkannya (Lee, dkk., 2019). Hasil visualisasi SOM yang sering menimbulkan ambigu ditutupi dengan FCM yang digunakan untuk memperhitungkan tingkat keanggotaan yang menciptakan batasan-batasan cluster.

Penelitian ini bertujuan untuk mengelompokkan performa belajar siswa berdasarkan aktivitas mereka selama belajar pada media pembelajaran digital dengan menggunakan kombinasi dari algoritme SOM dan FCM. Sebagai studi kasus, penelitian ini menggunakan log data yang diperoleh dari media pembelajaran Monsakun. Untuk mencapai tujuan yang telah disebutkan, penelitian ini mengangkat dua pertanyaan penelitian, yakni: (1) Berapakah jumlah cluster optimal dalam pengelompokan performa siswa dengan menggunakan kombinasi algoritme SOM dan FCM? (2) Apakah kombinasi dari algoritme SOM dan FCM memiliki hasil yang lebih baik apabila dibandingkan dengan SOM clustering konvensional berdasarkan nilai silhouette coeffiecient?

\section{METODE PENELITIAN}

Metodologi yang digunakan dalam penelitian ini ditunjukkan oleh Gambar 1. Tahapan pertama pada penelitian ini yaitu pengumpulan data. Penelitian ini menggunakan data primer dari sebuah media pembelajaran digital bernama Monsakun. Data tersebut merupakan data rekaman aktivitas (logdata) dari siswa kelas 1 SD yang menggunakan Monsakun di Jepang (Supianto, dkk., 2017). Adapun data yang digunakan dalam penelitian ini merupakan data rekaman aktivitas (log data) pada level kelima karena pada level inilah perbedaan performa belajar siswa dapat terlihat, berbeda dengan level-level sebelumnya yang karakteristik dari masing-masing siswanya tidak menimbulkan perbedaan yang berarti karena cenderung sama. 


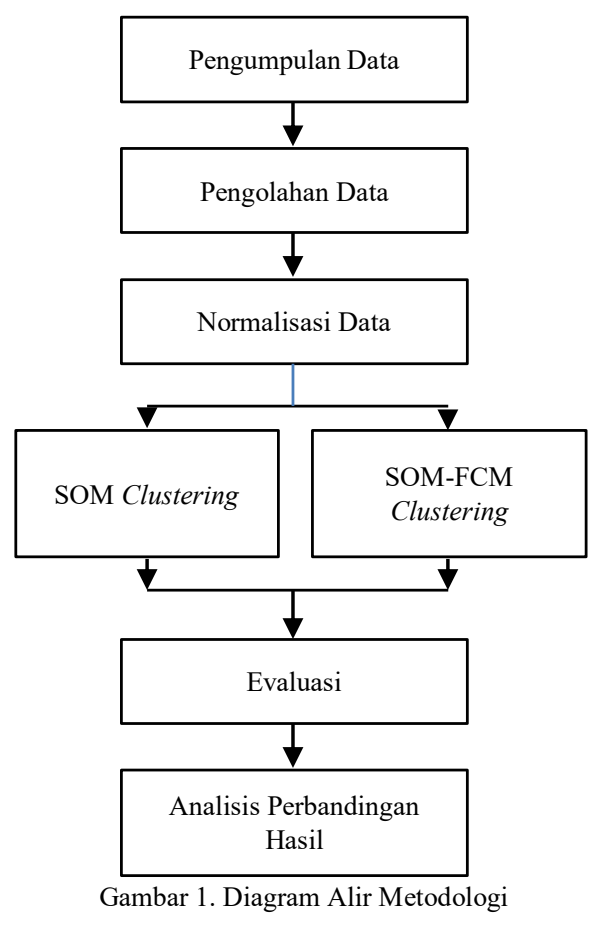

Data yang telah dipilih sebelumnya merupakan data berbentuk sequence. Data tersebut harus diolah terlebih dahulu menjadi fitur-fitur sesuai kebutuhan agar dapat diimplementasikan pada algoritme yang akan digunakan. Melalui pengolahan ini terpilihlah fitur-fitur yang meliputi id siswa, lama waktu yang dibutuhkan siswa, jumlah langkah yang dilakukan siswa, jumlah set, jumlah remove, jumlah penggunaan kartu 1, jumlah penggunaan kartu 2, jumlah penggunaan kartu 3, jumlah penggunaan kartu 4, jumlah penggunaan kartu 5, jumlah penggunaan kartu 6, jumlah langkah unik yang dilakukan siswa, dan jumlah error (Supianto, dkk., 2019). Contoh sampel data dari data yang digunakan ditunjukkan oleh Tabel 1.

\begin{tabular}{|c|c|c|c|c|c|c|c|c|c|}
\hline$\overline{2}$ & 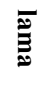 & 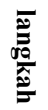 & $\mathscr{\leftrightarrow}$ & $\begin{array}{l}\overline{0} \\
\stackrel{3}{0} \\
0 \\
0\end{array}$ & $\Omega$ & $\cdots$ & ๙ & 郎 & ְִ \\
\hline 1 & 22 & 5 & 4 & 1 & 1 & $\ldots$ & 0 & 4 & 1 \\
\hline 2 & 65 & 15 & 9 & 6 & 1 & $\ldots$ & 0 & 14 & 2 \\
\hline 4 & 91 & 7 & 5 & 2 & 5 & $\ldots$ & 0 & 6 & 0 \\
\hline 5 & 19 & 5 & 4 & 1 & 1 & $\ldots$ & 0 & 4 & 1 \\
\hline 6 & 45 & 15 & 9 & 6 & 5 & $\ldots$ & 0 & 11 & 0 \\
\hline 8 & 61 & 31 & 17 & 14 & 1 & $\ldots$ & 4 & 20 & 3 \\
\hline 9 & 35 & 5 & 4 & 1 & 1 & $\ldots$ & 0 & 5 & 0 \\
\hline
\end{tabular}

Setelah fitur yang akan digunakan diperoleh, dilakukanlah normalisasi untuk menyamakan rentang nilai dari data. Penelitian ini menggunakan min-max normalization. Teknik normalisasi ini secara spesifik menyesuaikan data dalam kisaran nilai yang telah ditentukan sebelumnya dan memberikan hasil yang efektif dalam akurasi dan juga kecepatan untuk mencapai sebuah kondisi konvergen (Chamidah, dkk., 2012). Kemudian, data akan mulai dikelompokkan dengan algoritme Self-Organizing Map yang dikombinasikan dan tanpa dikombinasikan dengan algoritme Fuzzy C-Means. Langkah-langkah untuk algoritme Self-Organizing Map murni dirujuk dari jurnal (Siang, 2004). Sedangkan langkahlangkah untuk algortime Self-Organizing Map yang dikombinasikan dengan Fuzzy C-Means dirujuk dari jurnal (Lee, dkk., 2019) dengan langkah-langkah algorime Fuzzy C-Means yang dirujuk dari jurnal (Ye $\&$ Jin, 2016).

Tahapan selanjutnya setelah dilakukannya pengelompokan adalah proses evaluasi. Evaluasi dilakukan untuk mengetahui kualitas dari kelompok yang telah terbentuk. Menggunakan silhouette coefficient merupakan salah satu cara untuk melihat kualitas dari sebuah cluster. Selain itu, melalui hasil perhitungan silhouette coefficient kecocokan penempatan sebuah objek terhadap cluster-nya juga dapat diketahui (Handoyo, dkk., 2014). Setelah itu, hasil dari proses evaluasi akan dijadikan acuan dalam melakukan perbandingan. Adapun perbandingan dilakukan untuk mengetahui keberhasilan dari penerapan algoritme yang diusulkan.

Kemudian, melalui hasil perbandingan akan dilakukan analisis perbandingan untuk mengetahui apakah terdapat peningkatan yang signifikan secara statistik. Dalam menentukan jenis analisis statistik yang akan digunakan, diperlukan sebuah uji normalitas dengan menggunakan kormogorov smirnov. Jika hasil uji normalitas menunjukkan bahwa data terdistribusi normal, maka analisis perbandingan akan dilakukan dengan menggunakan t-test. Sebaliknya jika hasil uji menunjukkan bahwa data terdistribusi tidak normal, maka analisis perbandingan dilakukan dengan menggunakan wilcoxon test. Adapun langkah-langkah yang digunakan untuk proses perbandingan ini dirujuk dari buku (Kadir, 2015).

\section{HASIL DAN PEMBAHASAN}

Dalam menentukan hasil yang terbaik, dilakukan pengujian pada parameter-parameter yang ada pada setiap algoritme, baik Self-Organizing Map (SOM) maupun Fuzzy C-Means (FCM). Pengujian yang dilakukan pada parameter SOM adalah pengujian untuk menentukan jumlah output neuron yang tepat serta menentukan nilai learning rate yang optimum, sedangkan pengujian yang dilakukan pada parameter FCM adalah pengujian untuk menentukan jumlah cluster. Adapun setiap proses pengujian menggunakan metode Silhouette Coefficient yang didapatkan dari rata rata nilai Silhouette Coefficient tertinggi pada hasil pengujian yang dilakukan sebanyak 10 kali untuk masing-masing parameter yang diuji. Pengujian perlu dilakukan pada masing masing data karena setiap data memiliki karakteristik yang berbeda beda. Data yang digunakan untuk pengujian adalah data level 5 dengan total 12 assignment. 


\subsection{Pengujian Ukuran Map}

Proses pengujian ukuran map pada SOM dilakukan untuk mendapatkan jumlah output neuron yang cocok untuk setiap data yang ada. Proses pengujian dilakukan kepada setiap data satu-persatu. Ukuran map yang diujikan dimulai dari $3 \times 3$ hingga mencapai kondisi yang diinginkan, yakni saat jumlah titik yang muncul pada map sudah tidak bertambah lagi. Proses pengujian masing-masing assignment dilakukan sebanyak 10 kali percobaan untuk selanjutnya dilihat jumlah titik maksimum yang dihasilkan. Ukuran map yang terbaik merupakan ukuran map yang dapat menghasilkan titik dengan jumlah yang paling mendekati jumlah siswa di masing-masing assignment. Berikut merupakan contoh hasil pengujian pada data assignment 3 yang ditunjukkan oleh Tabel 2.

Tabel 2. Jumlah Titik pada SOM Assignment 3

\begin{tabular}{|c|c|c|c|c|c|}
\hline \multirow{2}{*}{$\begin{array}{c}\text { Percobaan } \\
\text { ke- }\end{array}$} & \multicolumn{5}{|c|}{ Jumlah Titik Saat Ukuran Map } \\
\hline & $3 \times 3$ & $5 \times 5$ & $10 \times 10$ & $25 \times 25$ & $50 \times 50$ \\
\hline 1 & 7 & 18 & 22 & 25 & 28 \\
\hline 2 & 7 & 15 & 24 & 24 & 22 \\
\hline 3 & 7 & 14 & 17 & 23 & 22 \\
\hline 4 & 7 & 17 & 19 & 21 & 26 \\
\hline 5 & 7 & 15 & 22 & 27 & 27 \\
\hline 6 & 7 & 15 & 18 & 28 & 20 \\
\hline 7 & 7 & 15 & 18 & 24 & 27 \\
\hline 8 & 7 & 15 & 22 & 21 & 28 \\
\hline 9 & 7 & 15 & 22 & 23 & 24 \\
\hline 10 & 7 & 17 & 17 & 28 & 23 \\
\hline
\end{tabular}

Berdasarkan hasil pengujian, titik tertinggi yang dapat diperoleh pada ukuran map 25x25 lebih tinggi dibandingkan dengan ukuran map 10x10, yang berarti proses reduksi dimensi yang dihasilkan oleh ukuran map 25×25 lebih baik dibandingkan dengan ukuran map 10x10 karena lebih mendekati jumlah siswa pada masing-masing assignment.

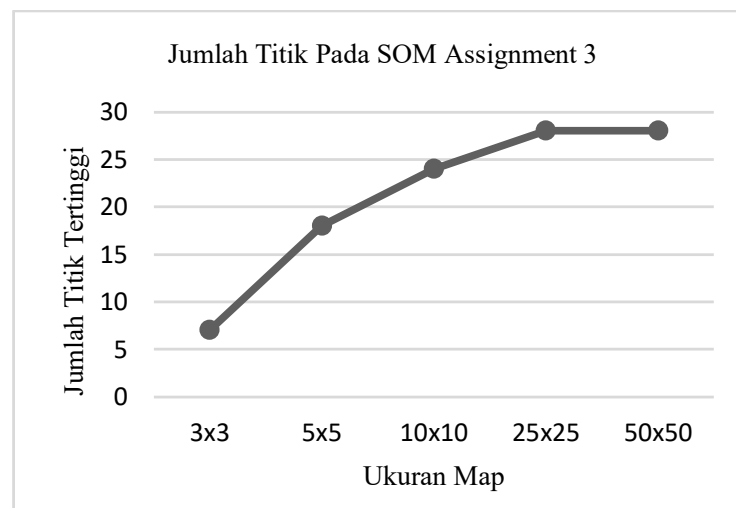

Gambar 2. Grafik Jumlah Titik Tertinggi pada SOM Assignment 3

Disisi lain, ukuran map 50x50 yang memiliki lebih banyak output neuron tidak menghasilkan jumlah titik yang lebih tinggi dibandingkan dengan ukuran map 25×25, melainkan cenderung sama atau lebih rendah, selain itu ukuran map 50x50 juga memiliki waktu komputasi yang lebih lama dibandingkan dengan ukuran map $25 \times 25$, sehingga ukuran map 50x50 tidak lebih baik dari ukuran map $25 \times 25$. Hal ini menunjukkan bahwa ukuran map terbaik yang akan digunakan untuk proses pengujian selanjutnya adalah $25 \times 25$. Untuk memperjelas, contoh visualisasi hasil pengujian milik assignment 3 ditunjukkan oleh Gambar 2.

Proses pengujian yang dilakukan pada assignment 3 juga dilakukan pada assignment lainnya. Melalui pengujian tersebut, assignment lain menunjukkan karakteristik yang sama sehingga ukuran map yang paling optimal untuk seluruh assignment adalah $25 \times 25$.

\subsection{Pengujian Nilai Learning Rate}

Nilai learning rate yang berbeda akan menghasilkan hasil yang berbeda pula.

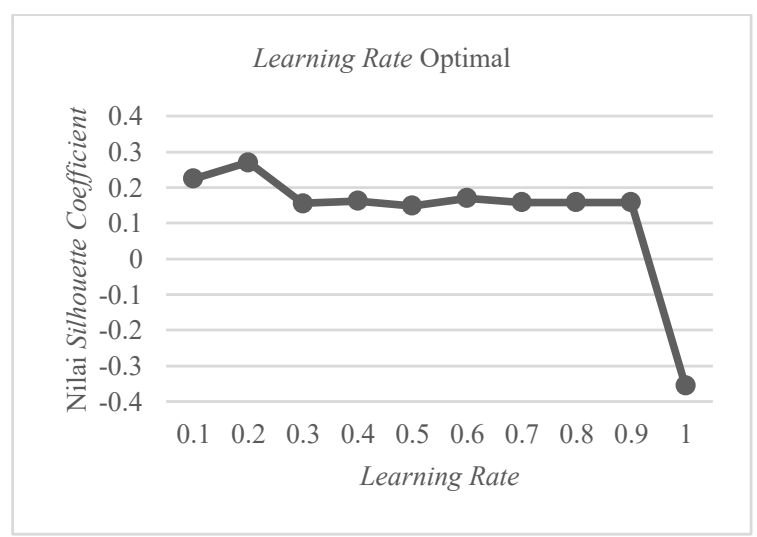

Gambar 3. Pengujian Learning Rate pada Assignment 3

Setelah ukuran map didapatkan, dilakukan pengujian tambahan pada SOM untuk mendapatkan nilai learning rate $(\alpha)$ yang nantinya akan digunakan pada proses selanjutnya. Berikut merupakan contoh hasil pengujian pada data assignment 3 yang ditunjukkan oleh Gambar 3.

Tabel 3. Learning Rate Optimal Assigment $1-12$

\begin{tabular}{cc} 
Tabel 3. Learning Rate Optimal & Assigment $1-12$ \\
\hline Assignment & Learning Rate Optimal \\
\hline Assignment 1 & 0.2 \\
Assignment 2 & 0.3 \\
Assignment 3 & 0.2 \\
Assignment 4 & 0.1 \\
Assignment 5 & 0.7 \\
Assignment 6 & 0.6 \\
Assignment 7 & 0.5 \\
Assignment 8 & 0.4 \\
Assignment 9 & 0.6 \\
Assignment 10 & 0.2 \\
Assignment 11 & 0.6 \\
Assignment 12 & 0.2 \\
\hline
\end{tabular}

Berdasarkan hasil pengujian, nilai silhouette coefficient tertinggi didapatkan ketika learning rate yang digunakan adalah 0.2 . Hal ini berarti, nilai learning rate yang akan digunakan oleh assignment 3 pada proses selanjutnya adalah 0.2 . Proses pengujian yang dilakukan pada assignment 3 juga dilakukan pada assignment lainnya. Melalui pengujian tersebut, setiap assignment mendapatkan nilai learning rate- 
nya masing-masing. Adapun hasil dari pengujian terhadap nilai learning rate ditunjukkan oleh Tabel 3.

\subsection{Pengujian Jumlah Cluster}

Pengujian dilakukan dengan menggunakan ukuran map yang telah ditentukan melalui pengujian ukuran map pada SOM, namun dikarenakan jumlah titik pada setiap percobaan sebelumnya selalu berubah, maka jumlah titik tertinggi dan terendah dari masing-masing assignment akan dijadikan bahan pengujian pada pengujian ini.

Pengujian untuk masing-masing assignment dilakukan sebanyak 10 kali percobaan, dan selanjutnya akan dihitung rata-rata dari nilai silhouette coefficient yang dihasilkan. Berikut merupakan contoh hasil pengujian pada jumlah titik tertinggi milik data assignment 3 yang ditunjukkan oleh Tabel 4.

Tabel 4. Pengujian Jumlah Cluster Optimal pada Assignment 3

\begin{tabular}{cccccc}
\hline \multirow{2}{*}{$\begin{array}{c}\text { Jumlah } \\
\text { cluster }\end{array}$} & \multicolumn{4}{c}{$\begin{array}{c}\text { Nilai Silhouette pada } \\
\text { percobaan ke- } \boldsymbol{i}\end{array}$} & \multirow{2}{*}{ Rerata } \\
\cline { 2 - 5 } & $\mathbf{1}$ & $\mathbf{2}$ & $\ldots$ & $\mathbf{1 0}$ & \\
\hline 2 & 0.80 & 0.80 & $\ldots$ & 0.80 & 0.80 \\
3 & 0.39 & 0.39 & $\ldots$ & 0.39 & 0.39 \\
4 & 0.42 & 0.42 & $\ldots$ & 0.42 & 0.42 \\
5 & 0.37 & 0.37 & $\ldots$ & 0.37 & 0.37 \\
6 & 0.34 & 0.34 & $\ldots$ & 0.34 & 0.36 \\
7 & 0.33 & 0.34 & $\ldots$ & 0.34 & 0.34 \\
8 & 0.33 & 0.34 & $\ldots$ & 0.34 & 0.34 \\
\hline
\end{tabular}

Berdasarkan hasil pengujian, cluster terbaik yang terbentuk adalah 2 cluster dengan nilai silhouette coefficient mencapai 0.8 . Untuk memperjelas, visualisasi hasil pengujian ditunjukkan oleh Gambar 4.

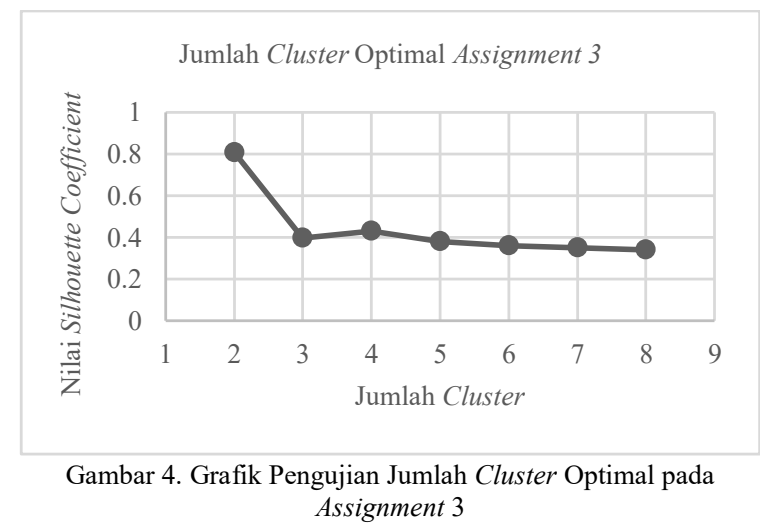

Merujuk ke pertanyaan penelitian pertama terkait jumlah cluster, setelah melalui berbagai pengujian didapatkanlah 2 cluster sebagai jumlah cluster optimal. Adapun 2 cluster yang ada menunjukkan bahwa performa belajar siswa pengguna Monsakun dapat dibagi menjadi dua jenis kelompok siswa, yakni kelompok siswa yang memiliki performa cukup baik dan kelompok siswa yang memiliki performa kurang baik.

\subsection{Perbandingan SOM dan SOM-FCM}

Pada penelitian ini, perbandingan dilakukan dengan membandingkan hasil algoritme SOM dengan dan tanpa penambahan FCM untuk membuktikan bahwa kombinasi dari algoritme SOM dan FCM mampu memberikan hasil yang lebih baik dibandingkan dengan algoritme SOM konvensional.

Pada pengujian ini, setiap titik yang dihasilkan pada algoritme SOM dianggap sebagai cluster, kemudian jumlah titik tersebut juga akan diinisialisasikan sebagai jumlah cluster pada kombinasi SOM dan FCM. Dikarenakan nilai acak yang kembali muncul pada saat inisialisasi cluster FCM, pada masing-masing assignment dilakukan sebanyak 10 kali percobaan, dan selanjutnya akan dihitung rata-rata dari nilai silhouette coefficient yang dihasilkan. Adapun hasil dari perbandingan algoritme SOM dengan dan tanpa penambahan FCM ditunjukkan oleh Gambar 5.

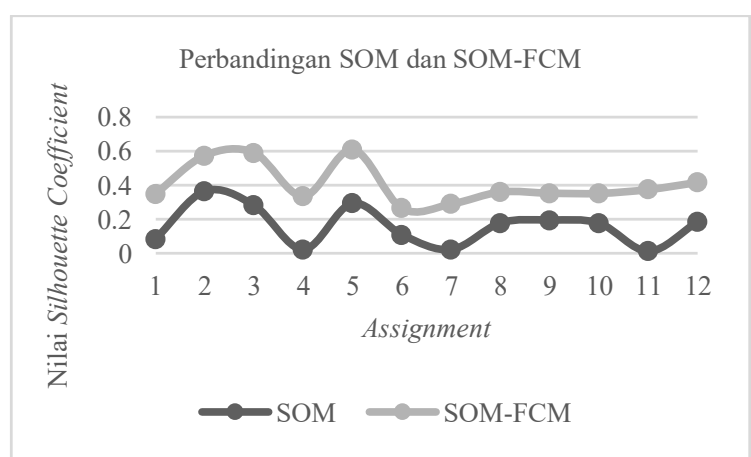

Gambar 5. Grafik Perbandingan SOM konvensional dan SOMFCM

Melalui perbandingan tersebut, dapat dilihat bahwa SOM-FCM menghasilkan nilai silhouette yang lebih tinggi dibandingkan SOM tanpa FCM. Lalu berdasarkan perbandingan tersebut, dilakukanlah uji normalitas dengan kormogorov smirnov. Uji normalitas ini menghasilkan nilai 0.879 untuk SOM dan 0.839 untuk SOM-FCM. Hal ini berarti data terdistribusi tidak normal karena nilai batas penerimaan dari tabel kormogorov smirnov adalah -0,391 sampai dengan 0,391.

Tabel 5. Hasil Pengujian Wilcoxon tes

\begin{tabular}{cc}
\hline Variabel & Nilai \\
\hline Positive Sum & 78 \\
\hline Negative Sum & 0 \\
\hline T Stat & 0 \\
\hline Critical Value & 13
\end{tabular}

Berdasarkan hasil dari uji normalitas dengan kormogorov smirnov yang menunjukkan bahwa data terdistribusi tidak normal, dilakukanlah Wilcoxon test sebagai analisis statistik yang cocok untuk data yang terdistribusi tidak normal. Adapun hasil dari Wilcoxon test ditunjukkan oleh Tabel 5. 
Hasil perhitungan Wilcoxon test menunjukkan bahwa nilai $t$ stat lebih kecil daripada nilai critical value yang berarti terdapat perbedaan yang signifikan antara hasil pengelompokan dengan SOM dan SOMFCM.

Merujuk pada pertanyaan penelitian kedua terkait peningkatan hasil yang diberikan oleh kombinasi algoritme SOM dan FCM, berbagai pengujian yang telah dilakukan membuktikan bahwa kombinasi dari algoritme SOM dan FCM mampu meningkatkan hasil dari algoritme SOM yang berdiri sendiri dengan perbedaan yang signifikan pada kualitas cluster berdasarkan nilai silhouette coefficient.

\section{KESIMPULAN}

Kesimpulan yang dapat ditarik setelah melakukan penelitian ini adalah melalui proses pengujian didapatkan jumlah ukuran map yang tepat pada algoritme Self-Organizing Map (SOM) yang digunakan pada penelitian ini adalah $25 \times 25$. Ukuran map yang telah didapatkan ini sekaligus menjadi penentu jumlah neuron output yang tepat digunakan pada penelitian ini, yakni 625 neuron. Selain itu, didapatkan pula jumlah cluster yang paling optimal pada algoritme Fuzzy C-Means (FCM) berdasarkan data keluaran algoritme SOM yang digunakan pada penelitian ini adalah 2 cluster pada setiap assignment. Melalui cluster yang telah terbentuk, siswa terbagi atas siswa yang memiliki performa cukup baik dalam penggunaan Monsakun dan siswa yang memiliki performa kurang baik dalam penggunaan Monsakun.

Berdasarkan parameter optimal yang telah didapatkan, pengujian yang dilakukan untuk membandingkan SOM dengan dan tanpa penambahan FCM telah membuktikan bahwa kombinasi algoritme SOM dan FCM mampu memberikan hasil yang lebih baik dibanding algoritme SOM tanpa penambahan FCM. Hal ini juga telah diperkuat oleh hasil Wilcoxon test yang menunjukkan bahwa terdapat perbedaan yang signifikan antara hasil dari keduanya.

Saran untuk penelitian selanjutnya yaitu parameter-parameter yang masih menggunakan nilai acak (random) seperti inisialisasi bobot awal pada algoritme SOM dan matriks partisi (matriks keanggotaan) awal pada algoritme FCM selanjutnya akan lebih baik apabila melalui sebuah proses yang dapat menghasilkan nilai terbaik agar hasilnya lebih optimal.

\section{DAFTAR PUSTAKA}

ALIAS, U. F., AHMAD, N. B. \& HASAN, S., 2017. Mining of E-learning Behavior using SOM Clustering. ICT International Student Project Conference (ICT-ISPC), Volume 6.

ARSYAD, A., 2010. Media Pembelajaran. Jakarta: PT Raja Grafindo Persada.
BRAUER, C., 2012. An Introduction to SelfOrganizing Maps. Proseminar Artificial Intelligence.

CHAMIDAH, N., WIHARTO \& SALAMAH, U., 2012. Pengaruh Normalisasi Data pada Jaringan Syaraf Tiruan Backpropagasi Gradient Descent Adaptive Gain (BPGDAG) untuk Klasifikasi. JURNAL ITSMART, Volume 1, pp. 28-33.

HANDOYO, R., MANGKUDJAJA, R. \& NASUTION, S. M., 2014. Perbandingan Metode Clustering Menggunakan Metode Single Linkage dan K-Means Pada Pengelompokan Dokumen. JSM STMIK Mikroskil, Volume 15, pp. 73-82.

HAN, J., PEI, J. \& KAMBER, M., 2012. Data Mining: Concept and Techniques. 3rd ed. Waltham: Morgan Kaufmann Publisher.

KADIR., 2015. Statistika Terapan. Dalam Konsep, Contoh dan Analisis Data dengan Program SPSS/Lisrel dalam Penelitian. Depok: PT Raja Grafindo Persada

KOHONEN, T., 2001. Self-Organizing Map. 3rd ed. New York: Springer.

KUSRINI \& LUTHFI, E. T., 2009. Algoritma Data Mining. Yogyakarta: C.V Andi OFFSET (Penerbit ANDI).

LAROSE, D. T., 2005. Discovering Knowledge In Data: An Introduction to Data Mining. United States of America: John Wiley \& Sons Inc.

LEE, K. J., YUN, S. T., KIM, K. H., LEE, J. H., \& LEE, S. H., 2019. The combined use of selforganizing map technique and fuzzy c-means clustering to evaluate urban groundwater quality in Seoul metropolitan city, South Korea. Journal of Hydrology, Volume 569, pp. 685-697.

MUHASIM, 2017. Pengaruh Tehnologi Digital, Terhadap Motivasi Belajar Peserta Didik. Jurnal Studi Keislaman dan Ilmu Pendidikan, Volume 5, pp. 53-77.

SADIMAN, A. S., 2008. Media Pembelajaran. Jakarta: Raja Grafindo Persada.

SIANG, J. J., 2004. Jaringan Syaraf Tiruan \& Pemrogramannnya Menggunakan Matlab. Yogyakarta: ANDI Publisher.

SUPIANTO, A. A., HAYASHI, Y. \& HIRASHIMA, T., 2016. Visualizations of problem-posing activity sequences toward modeling the thinking process. Research and Practice in Technology Enhanced Learning.

SUPIANTO, A. A., CHRISTYAWAN, T. Y., HAFIS, M., HAYASHI, Y., HIRASHIMA, T., \& HASANAH, N., 2019. Feature Dimensionality Reduction for Visualization and Clustering on Learning Process Data. 2019 International Conference on Sustainable Information Engineering and Technology (SIET), pp. 84-89. 
SUPIANTO, A. A. \& HAFIS, M., 2018. GTRAS: Graphical Tracking Activity System for Problem-Posing Learning Process Insights. ICACSIS.

SUPIANTO, A. A., HAYASHI, Y. \& HARASHIMA, T., 2017. Model-Based Analysis of Thinking in Problem Posing as Sentence Integration Focused on Violation of the Constraints. Research and Practice in Technology Enhanced Learning.

SUPIANTO, A. A., HAYASHI, Y. \& HIRASHIMA, T., 2017. An Investigation of Learner's Actions in Posing Arithmetic Word Problem on an Interactive Learning Environment. IEICE Transactions on Information and Systems, Volume 100(11), pp. 2725-2728.

SUPIANTO, A. A., WICAKSONO, S. A., BACHTIAR, F. A., HERLAMBANG, A. D., HAYASHI, Y., \& HIRASHIMA, T., 2019. Web-based Application for Visual Representation of Learners' Problem-Posing Learning Pattern. Journal of Information Technology and Computer Science, Volume 4(1), pp. 103-115.

SUPRATMAN, E. \& PURWANINGTIAS, F., 2018. Pengembangan Media Pembelajaran ELearning Berbasis Schoology. Jurnal Informatika: Jurnal Pengembangan IT (JPIT), Volume 3, pp. 310-315.

YE, A.-X. \& JIN, Y.-X., 2016. A Fuzzy C-Means Clustering Algorithm Based on Improved Quantum Genetic Algorithm. International Journal of Database 
Halaman ini sengaja dikosongkan 